\title{
Advanced oxidation technologies: advances and challenges in Iberoamerican countries
}

\author{
Vítor J. P. Vilar • Sixto Malato • Dionysios D. Dionysiou
}

Received: 29 May 2014 / Accepted: 4 June 2014 / Published online: 27 June 2014

(C) Springer-Verlag Berlin Heidelberg 2014

7th Congress of Environmental Application of Advanced Oxidation Technologies ( $\left.7^{\circ} \mathrm{EPOA}\right)$ and 1 st Iberoamerican Congress of Advanced Oxidation Technologies ( $\left.1^{\circ} \mathrm{CIPOA}\right)$

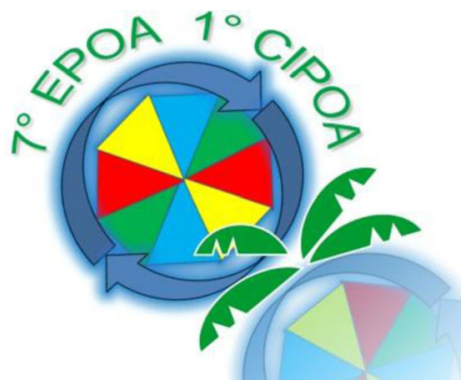

In Iberoamerican countries, more than 80 million people lack access to clean drinking water and 100 million people lack adequate sanitation. This requires a tremendous amount of research to develop appropriate technologies and infrastructure to improve the community socioeconomic situation and

Responsible editor: Philippe Garrigues

\section{J. P. Vilar $(\triangle)$}

LSRE-Laboratory of Separation and Reaction Engineering-Associate Laboratory LSRE/LCM, Departamento de Engenharia Química, Faculdade de Engenharia, Universidade do Porto, Rua Dr. Roberto Frias, 4200-465 Porto, Portugal

e-mail: vilar@fe.up.pt

\section{S. Malato}

Plataforma Solar de Almería, Carretera Senés Km 4, Tabernas, Almería 04200, Spain

e-mail: sixto.malato@psa.es

\section{D. Dionysiou}

Environmental Engineering and Science Program, Department of Biomedical, Chemical and Environmental Engineering, 705

Engineering Research Center, University of Cincinnati, Cincinnati, OH 45221-0012, USA

e-mail: dionysios.d.dionysiou@uc.edu protect human health, in agreement with the UN Millennium Development Goals. As reported in the "Workshop on Nanotechnologies for Environmental Remediation" (Rickerby and Morrison 2007), the development of photocatalytic depollution technologies that use solar energy, or even artificial light, can provide sustainable solutions for the production of clean and safe water in developed and developing countries. In particular, such solutions can be very beneficial for remote and isolated communities with insufficient infrastructure but leaving in locations of high yearly sunshine.

Despite its great potential as a green technology for water purification, $\mathrm{TiO}_{2}$ photocatalysis has not yet reached a mature level for large-scale applications.

Publications on solar-driven photocatalytic processes increased continuously during the last 10 years, achieving more than 2,000 papers in 2013, representing more than $50 \%$ of the publications regarding photocatalysis (Fig. 1).

Publications are divided into articles $(10,510)$, conference papers (1,064), reviews (468), and others (53). Approximately $38 \%$ of the articles regarding solar photocatalysis are from China (Fig. 2).

Although Iberoamerican countries are among the sunniest countries in the world and have serious water scarcity problems, they have only contributed to $10 \%$ of the articles published, with $46 \%$ being from Spain (Fig. 3).

This special issue of Environmental Science and Pollution Research contains a selection of 20 papers presented at the 7 th Congress of Environmental Application of Advanced Oxidation Technologies ( $\left.7^{\circ} \mathrm{EPOA}\right)$ and the 1 st Iberoamerican Congress of Advanced Oxidation Technologies ( $\left.1^{\circ} \mathrm{CIPOA}\right)$, which were held in Recife, Brazil, from 15 to 18 October 2013.

The goal of CIPOA conferences was to provide a platform to spread the knowledge in advanced oxidation processes around the Iberoamerican countries and attract new young researchers to this research field. 


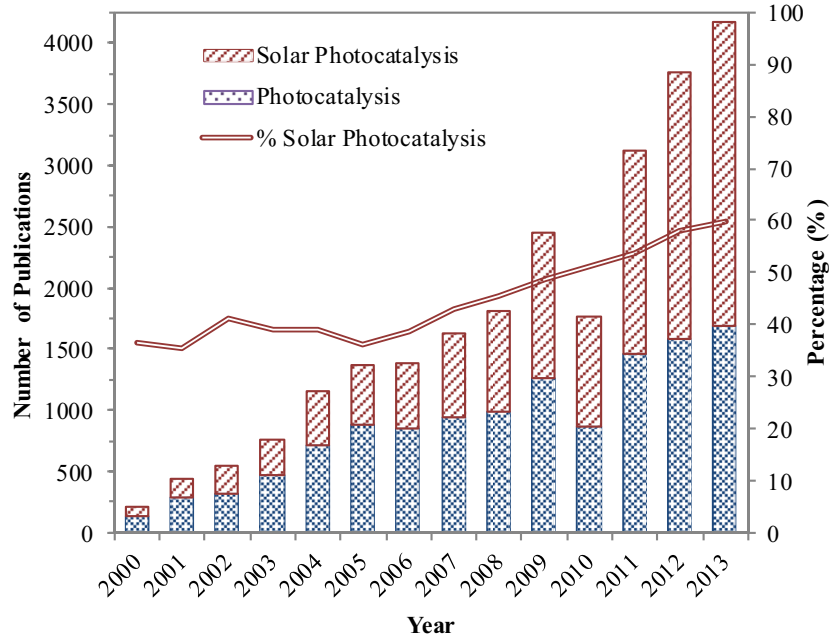

Fig. 1 Number of publications concerning photocatalysis and solardriven photocatalysis per year: SCOPUS search results in the period 2000-2013 (keywords: "Photocatalysis" and "Solar" within these results)

The $7^{\circ} \mathrm{EPOA}$ and $1^{\circ} \mathrm{CIPOA}$ meetings brought together more than 200 academics, professionals, and policy makers from different Iberoamerican countries such as Brazil, Spain, Portugal, Argentina, Mexico, Colombia, Uruguay, Chile, and Peru. In addition, researchers from France, Germany, Switzerland, Canada, and the USA also attended the meetings. The conference program was rather dense and rich, offering a considerable variety of topics covered, with 12 keynotes, 80 oral presentations, 74 short oral communications, and 70 posters. The short oral communications gave the opportunity to young researchers to present their research work and to interact with senior researchers. The topics covered included (i) new photocatalytic materials; (ii) environmental remediation of water, wastewater, air, and soil, using different advanced oxidation technologies; and (iii) integration of AOPs with other technologies, such as biological oxidation, adsorption, coagulation/flocculation, and membranes.

Several papers selected from the scientific presentations of $7^{\circ} \mathrm{EPOA} / 1^{\circ} \mathrm{CIPOA}$ outline new materials (N-modified titania nanotubes, $\mathrm{TiO}_{2} / \mathrm{Ag}, \mathrm{TiO}_{2}$-activated carbon) with remarkable photocatalytic activity for the degradation of different organic

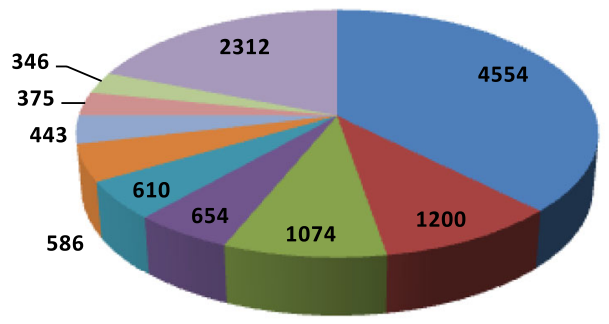

China
United States
$\square$ Japan
$\square$ India
South Korea
$\square$ Spain
Germany
France
Italy
$\square$ Others

Fig. 2 Number of articles concerning solar-driven photocatalysis per country: SCOPUS search results in the period 2000-2013 (keywords: "Photocatalysis" and "Solar" within these results)

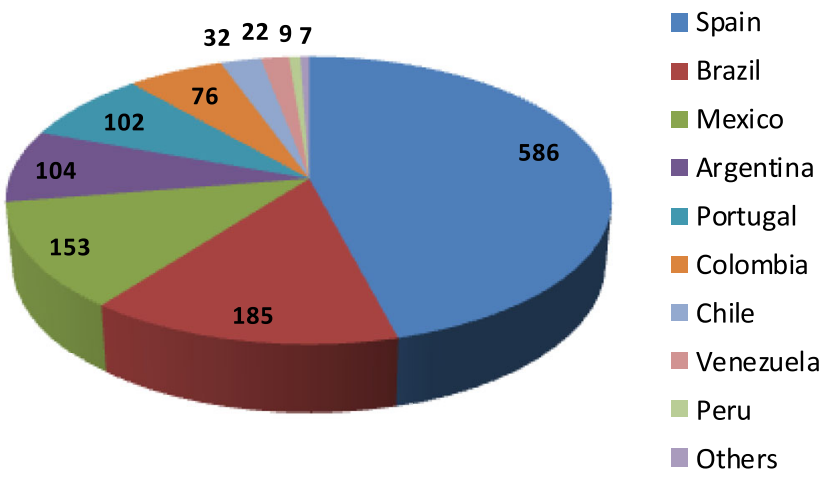

Fig. 3 Number of articles concerning solar-driven photocatalysis per Iberoamerican country: SCOPUS search results in the period 2000 2013 (keywords: "Photocatalysis" and "Solar" within these results)

pollutants in water and air. The classical heterogeneous and homogeneous Fenton, photo-Fenton, and solar driven photoFenton processes, catalyzed by ferrous iron, ferric iron, zerovalent iron, or iron oxides, such as goethite, montmorillonite clay modified with iron, Fe particles dispersed in a carbon matrix active, iron oxide pillared clay with magnetic properties, mixed material clay/Fe, and siderurgical iron sludges, were also evaluated for remediation processes. Two papers also deal with reaction pathways and kinetic modelling, and another two papers use ultrasonic and ozonation processes.

This special issue also provides an overview of some photocatalytic water/air depollution systems that utilize solar energy and could be used in remote areas not reached from the grid, as well as photocatalytic applications and challenges in Iberoamerican countries.

The guest editors would like to thank all the authors for the innovative scientific contributions to this special issue, the reviewers whose comments and suggestions were extremely important to achieve high-quality papers, as well as the institutions and companies that sponsored $7^{\circ} \mathrm{EPOA} / 1^{\circ} \mathrm{CIPOA}$.

A final word of thanks to ESPR editor-in-chief Philippe Garrigues and the editorial assistant Emmanuelle PignardPéguet for their assistance/help/support in the preparation of this special issue.

Vítor Vilar wishes to thank the FCT Investigator 2013 Programme (IF/01501/2013). Sixto Malato wishes to thank the Spanish Ministry of Economy and Competitiveness financial support under the AQUAFOTOX Project (Reference: CTQ2012-38754-C03-01). Dionysios Dionysiou also acknowledges support from the University of Cincinnati through a UNESCO co-chair professor position on "Water Access and Sustainability."

\section{References}

Rickerby D, Morrison M (2007) Report from the work-shop on nanotechnologies for environmental remediation. JRC Ispra, http://www. nanowerk.com/nanotechnology/reports/reportpdf/report101.pdf 


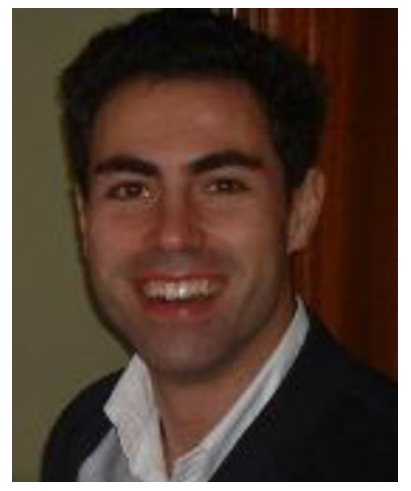

Dr. Vilar was born in Miragaia, Porto, Portugal, in April 1978. He is principal researcher in the LSRELaboratory of Separation and Reaction Engineering-Associate Laboratory LSRE/LCM, Faculty of Engineering, University of Porto (FEUP). He is also "Special Visiting Researcher" in the Federal University of Santa Catarina, Brazil, supported by the Ciência Sem Fronteiras Program. He received the graduation in Chemical Engineering in 2001 and the Ph.D. in Chemical Engineering in 2006 at FEUP. He is the author

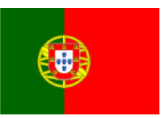
and co-author of more than 200 scientific publications, including 7 book chapters, 97 papers in international scientific periodicals with peer review, and more than 100 communications in conference proceedings. His main research interests focus in environmental assessment and monitoring of surface waters and environmental friendly technologies for pollution control, particularly in the application of solar advanced oxidation processes for water and air treatment, integration of chemical and biological processes for the treatment of recalcitrant wastewaters, and valorization of natural materials for separation and recovery of heavy metals, oil and grease. He has been involved in 5 international and 10 national $R \& D$ projects and 3 contracts with private companies related to the development of environmental friendly technologies for pollution control. V. Vilar completed the supervision of 10 researchers granted by projects, 15 master students, $5 \mathrm{Ph} . \mathrm{D}$. students, and 5 postdoctoral researchers. Currently, he is the supervisor of $15 \mathrm{Ph} . \mathrm{D}$. students, 4 postdoctoral researchers, and 3 researchers granted by projects. He has been doing tutorial teaching at FEUP in several course units of the integrated master in chemical engineering and environmental engineering. He was also involved in the organization of three international scientific conferences and other events/videos for promotion of science and technology. $\mathrm{He}$ is also the vice president of the Iberoamerican Congress of Advanced Oxidation Technologies (CIPOA).

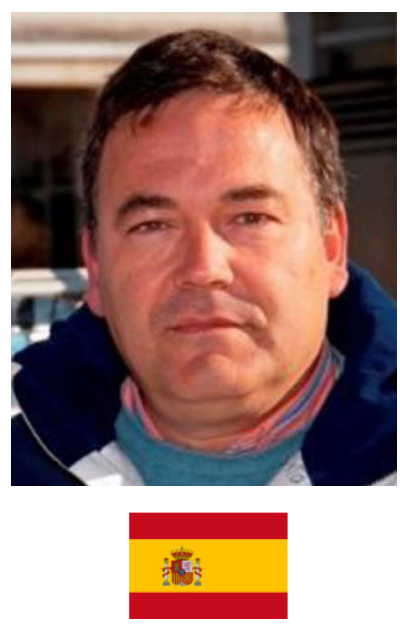

Dr. Malato was born on May 10, 1964, and has a Ph.D. in Chemical Engineering. He is the director of Plataforma Solar de Almeria (www. psa.es) and Joint Research Center (Univ. Almería-CIEMAT) of R\&D in Solar Energy (CIESOL). http:// www.ciesol.es. He has 25 years of experience working at different sectors. He works at the Plataforma Solar de Almeria (PSA-CIEMAT) in all the projects linked to solar water treatment. Concretely, he has been involved in $16 \mathrm{EU}$ and 20 National related to the development of solar wastewater treatment technologies and has been involved in the design and construction of all the experimental pilot plants for solar detoxification of industrial waste water in Europe. He is the author of 1 book and co-author of 16 books as well as 56 chapters in others. He has also co-authored more than 190 publications in indexed international journals and 4 patents. He has directed $11 \mathrm{Ph} . \mathrm{D}$. thesis. He is also the assistant editor of Environmental Chemistry Letters (Ed. Spinger) and Journal of Advanced Oxidation Technologies (Sci.\& Technol. Network, Inc.). Dr. Malato is a member of the editorial board of Catalysis Today (Elsevier) and Photochemical and Photobiological Sciences. (RSC Publishing). He has a h-index (http://www.scopus.com, December 2013) of 51. He has received awards from The Jury's Grand Prix of "European Grand Prix for Innovation Awards" (11 December 2004, Mónaco; http://www.european-grandprix.com/index_en.htm) and Jaime I Price in Environmental Protection, 2011 (Most important in science in Spain; http://www.fvea.es/medioambiente.html).

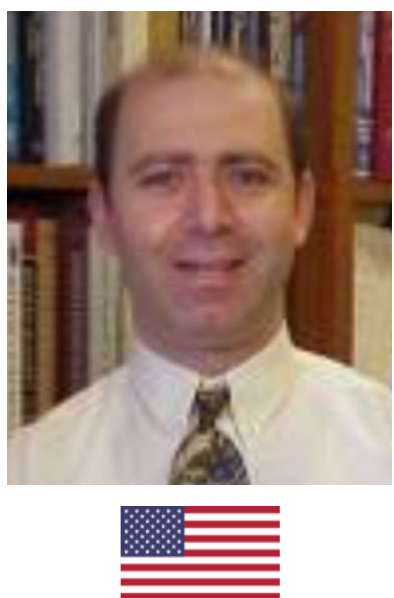

Professor Dionysiou was born on the Island of Cyprus. He is currently a UNESCO Chair Professor on "Water Access and Sustainability" and a Herman Schneider Professor of Environmental Engineering at the University of Cincinnati where he teaches courses on drinking water quality and treatment, advanced unit operations for water treatment, advanced oxidation technologies, and physical-chemical processes for water quality control. His research interests include treatment of water contaminated by harmful algal blooms with conventional and advanced technologies, advanced technologies for water treatment, advanced oxidation technologies, transition metal-based chemical oxidation, and nanotechnology. Dr. Dionysiou is the author or co-author of over 180 refereed journal publications, over 90 conference proceedings, 17 book chapter publications, 17 editorials, and more than 450 presentations. He is currently co-editing three books on water reuse, harmful algal blooms, and photocatalysis. Dr. Dionysiou's work received over 6,000 citations with an $\mathrm{H}$ factor of 45 . He has currently numerous national and international collaborations. Dr. Dionysiou has received funding from NSF, US EPA, NASA, NOAA/CICEET, USGS, USDA, Cyprus Research Foundation, and DuPont. He is currently one of the editors of Chemical Engineering Journal (Elsevier), Editor of the Journal of Advanced Oxidation Technologies, and Special Issue Editor and Associate Editor for the Journal of Environmental Engineering (ASCE). He is a member of the Editorial Boards of ten other journals. He has previously served as Associate Editor of Water Environment Research (WEF) (2006-2011) and as member of the Editorial Board of Environmental Progress (now renamed as Environmental Progress and Sustainable Energy) (AIChE) (2003-2009). He is program chair of the Environmental Chemistry Division of ACS and is a member of many committees of several professional societies (i.e., ACS, AEESP, AWWA, WEF, IWA). Dr. Dionysiou has been featured in several international symposia, professional meetings, and scientific publications, including an interview on "Cleaning up water" published on July 5, 2011, in the Chemistry World magazine of the Royal Society of Chemistry.

http://www.rsc.org/chemistryworld/News/2011/July/05071101.asp 